\title{
EVALUASI KINERJA TERMINAL INDUK PAL 6 KOTA BANJARMASIN
}

\author{
Bagus Priambodo Prima ${ }^{1)}$, Utami Sylvia Lestari ${ }^{2)}$ \\ Fakultas Teknik, Jurusan Teknik Sipil, Universitas Lambung Mangkurat \\ ${ }^{1)}$ Email: baguspriambodoprima@yahoo.com \\ ${ }^{2)}$ Email: utami.s.lestari@ulm.ac.id
}

\begin{abstract}
ABSTRAK
Terminal Induk PAL 6 Kota Banjarmasin terdapat di wilayah Kota Banjarmasin yang bertipe tipe B. Penelitian ini bertujuan untuk mengetahui dan menganalisis operasional Terminal Induk PAL 6 Kota Banjarmasin pada saat ini dan mengetahui kinerja dari pelayanan-pelayanan yang diberikan oleh terminal kepada para pengguna, serta mengetahui alternatif yang sesuai untuk digunakan agar terminal dapat beroperasi secara optimal. Evaluasi Kinerja Terminal ini menganalisis fasilitas-fasilitas dengan menggunakan Importance Performance Analisis. Survei dilakukan pada jam operasional terminal serta lokasi survei dilakukan di dalam Terminal Induk PAL 6 Kota Banjarmasin. Survei yang dilakukan yaitu survei fasilitas pelayanan yang diberikan oleh terminal kepada para pengguna terminal dan survei wawancara kuisoner kepada para pengguna terminal sebanyak 220 responden. Survei kuisioner wawancara dalam penelitian ini memeliki dua jenis kuisioner, yaitu kuisioner kepentingan dan kuisioner kepuasan. Kuisioner kepentingan ditujukan kepada stakeholder atau pengelola terminal, sedangkan kuisioner kinerja atau kepuasan ditujukan kepada para pengguna terminal. Dari hasil penelitian didapatkan pada analisis IPA diperoleh tingkat kesesuaian sebesar (70,74\%), sehingga secara keseluruhan kinerja kualitas pelayanan menurut kriteria nilai Customer Satisfaction Index (CSI) berada pada kategori Baik.
\end{abstract}

\section{Kata Kunci : Terminal Induk PAL 6 Kota Banjarmasin, Kinerja Terminal, IPA}

\section{ABSTRACT}

PAL 6 Induk Terminal of Banjarmasin city is the type of terminal type B. The purpose of this study was to determine and analyze the operational PAL 6 Induk Terminal of Banjarmasin city at this time and know the performance of services provided by the terminal to the users, as well as the alternative of appropriate strategies to be executed so that the terminal can operate optimally. This Terminal Performance Evaluation is facilities to analyze variables by using Importance-Performance Analysis. The survey was conducted on the operating hours of the terminal as well as the location of the survey carried out in the PAL 6 Induk Terminal of Banjarmasin city. Surveys conducted surveying service facilities provided by the terminal to the user terminal and the interview survey questionnaires to the terminal users as much as 220 respondents. The survey questionnaire interviews in this study to own two types of questionnaires, the interests questionnaires, and satisfaction questionnaires. A questionnaire was addressed to stakeholders interests or terminal manager, while the performance or satisfaction questionnaire addressed to the user terminal. From the results, the IPA analysis obtained a concordance rate of $(70.74 \%)$ while the performance or satisfaction questionnaire addressed to the terminal user. So that the overall performance of service quality according to the criteria of value Customer Satisfaction Index (CSI) is in a Good category.

Keywords: PAL 6 Induk Terminal of Banjarmasin City, Terminal Performance, IPA 


\section{PENDAHULUAN}

\section{Latar Belakang}

Transportasi adalah suatu kegiatan untuk memindahkan manusia dan atau barang dari satu tempat ke tempat lain dan termasuk sarana dan prasarana yang digunakan untuk memindahkannya. Kebutuhan manusia untuk dapat berpindah dari satu tempat ke tempat lain inilah yang menyebabkan pergerakan transportasi tersebut. Terminal penumpang merupakan prasarana yang menjadi komponen penting dalam suatu sistem transportasi. Terminal didefinisikan sebagai titik dimana keluar dan masuknya penumpang dan barang dari sistem transportasi, Terminal juga dapat menjadi tempat bergantinya route atau moda. Keputusan Menteri Perhubungan RI dalam KM 31 tahun 1995 mendefinisikan terminal menjadi dua yaitu adanya Terminal Penumpang dan Terminal barang. Terminal penumpang adalah prasarana untuk keperluan menaikan dan menurunkan penumpang, sedangkan terminal barang adalah prasarana untuk keperluan memuat dan membongkar barang serta perpindahan antar moda transportasi.

Banjarmasin yang dikenal sebagai kota jasa dan perdagangan sangat mengandalkan sistem transportasi jalan dengan pergerakan penumpang angkutan umum dan barang yang tinggi. Untuk moda jalan, simpul pergerakannya lebih dikenal dengan Terminal. Fungsi utama terminal diantaranya adalah sebagai titik awal-akhir operasi transportasi (trayek), tempat pergantian moda atau rute/trayek, bongkar-muat barang, naik turun penumpang, termasuk untuk tempat pemeliharaan sarana dan pelayanan penumpang lain.

Terminal Induk KM.6 merupakan terminal tipe B yang berfungsi sebagai terminal induk, karena Terminal KM.17 yang memiliki regional tipe A tidak difungsikan. Keadaan Terminal Induk KM.6 di Banjarmasin dengan luas semula 2,5 Ha, saat ini yang digunakan untuk terminal tersisa hanya $1 \mathrm{Ha}$ saja, karena sebagian dari area terminal telah digunakan untuk pembangunan perkotaan.

Aktifitas di Terminal Induk KM.6 ini cukup padat karena melayani Angkutan Kota Dalam Propinsi (AKDP), Angkutan Kota Antar Propinsi (AKAP), dan Angkutan Kota (AK). Melihat kondisi dan aktifitas Terminal Induk KM.6 ini cukup padat, membuat kondisi terminal semakin memprihatinkan. Selain terlihat kumuh, tampak tidak ada pengaturan sehingga terlihat kacau balau dalam memarkir kendaraan. Oleh karena itu, sistem operasional angkutan umum harus benar-benar diatur sedemikian rupa sehingga tidak memacu operator angkutan umum untuk tidak berdisiplin. Maka peran terminal sebagai tempat pengatur operasional angkutan umum harus dapat berfungsi dengan baik. Sebagai salah satu upaya optimasi jaringan transportasi, evaluasi terhadap kinerja Terminal Induk KM.6 Kota Banjarmasin perlu dilakukan.

\section{Rumusan Masalah}

Penelitian ini dilakukan untuk mengetahui:

1. Bagaimana keadaan Terminal Induk Kota Banjarmasin saat ini?

2. Bagaimana tanggapan para pengguna terhadap kinerja Terminal Induk Kota Banjarmasin saat ini?

3. Bagaimana saran perbaikan terkait permasalahan kinerja pelayanan Terminal Induk Kota Banjarmasin?

\section{Tujuan Penelitian}

Tujuan dari penelitian ini adalah:

1. Mengetahui keadaan Terminal Induk Kota Banjarmasin saat ini.

2. Mengetahui tanggapan para pengguna terhadap kinerja Terminal Induk Kota Banjarmasin saat ini.

3. Memberikan saran perbaikan terkait permasalahan kinerja pelayanan Terminal Induk Kota Banjarmasin.

\section{Batasan Masalah}

Agar penelitian lebih terarah dan juga memberi pembahasan yang lebih rinci, maka dibuat batasan studi yang tidak mengurangi saran studi. Batasan masalah pada penelitian ini adalah sebagai berikut:

1. Terminal yang dievaluasi pada penelitian ini adalah terminal bus penumpang angkutan umum darat.

2. Kuisioner yang disusun dengan menggunakan Importance Performance Analysis

3. Penilaian kepuasan pengguna terhadap pelayanan yang diberikan pengelola menggunakan Kriteria Nilai Customer Satisfaction Index (CSI) yang telah diiberi kriteria penilaian oleh pengelola terminal. 


\section{METODE PENELITIAN}

\section{Tahap Identifikasi Masalah}

Kegiatan tahap ini meliputi kunjungan ke lapangan khususnya ke Terminal Induk KM. 6 Banjarmasin, untuk melihat langsung kinerja dari Terminal Induk KM. 6 tersebut dan permasalahannya berkaitan dengan topik ini.

\section{Tahap Pengumpulan Data}

Ada dua kegiatan yang ada di dalam pengumpulan data dalam penulisan ini yaitu meliputi pengumpulan data primer dan pengumpulan data sekunder.

\section{Data Primer}

Untuk memperoleh data primer dalam laporan ini menggunakan survey wawancara. Survey wawancara yang dilakukan pada jam pelayanan terminal ini, terbagi menjadi dua kuisioner. Kuisioner untuk pemberi pelayanan dan kuisioner untuk pengguna terminal.

\section{Data Sekunder}

Pengumpulan data sekunder dilakukan melalui pengumpulan data yang berasal dari instansi terkait dalam hal ini adalah Dinas Lalu Lintas dan Angkutan Jalan (DLLAJR) Provinsi Kalimantan Selatan serta data yang berasal dari pengelola terminal. Data sekunder ini meliputi:

1. Peta Lokasi

2. Lay out terminal

3. Fluktuasi jumlah angkutan umum dan penumpang

\section{Tahap Pengolahan Data}

Data yang diperoleh dari lapangan, terlebih dahulu diolah untuk memberikan gambaran yang sesuai dengan kondisi yang ada pada saat ini. Hasil pengolahan data ini disajikan dalam bentuk tabel.

\section{Tahap Analisis Data}

Setelah selesainya tahap pengolahan data, tahap selanjutnya adalah tahap analisis data. Tahapan ini mengerjakan:

1. Identifikasi dan klasifikasi data-data yang dikumpulkan

Data yang telah didapatkan dari kuisioner yg diisi oleh pengguna dan pengelola terminal terlebih dahulu kita identifikasi dan klasifikasi.
2. Uji Validitas dan Reliabilitas dengan SPSS Pengujian validitas dan reliabilitas digunakan untuk mengukur sah, atau valid tidaknya suatu kuesioner dan sejauh mana pengukuran dari suatu tes tetap konsisten setelah dilakukan berulang-ulang terhadap subjek dan dalam kondisi yang sama.

3. Analisis menggunakan metode Importance Performance Analysis

Metode IPA berguna untuk mengetahui faktor apa saja yang berpengaruh terhadap kualitas pelayanan Terminal Induk PAL 6 Kota Banjarmasin dengan cara mengukur tingkat kepentingan dengan tingkat kepuasan melalui beberapa jenis pelayanan yang diberikan pengeloola terminal terhadap pengguna seperti Informasi yang jelas dan mudah dibaca (Visual/Audio), Loket agen perjalanan, Ruang Tunggu dan lainnya. Skala yang digunakan dalam pembuatan kuisioner adalah skala likert yang memiliki 5 tingkatan seperti pada tabel 1 berikut:

Tabel 1. Skala Likert

\begin{tabular}{|c|c|c|}
\hline $\begin{array}{c}\text { Tingkat } \\
\text { Kepentingan }\end{array}$ & Skor & $\begin{array}{c}\text { Tingkat } \\
\text { Kepuasan }\end{array}$ \\
\hline Sangat Penting & 5 & Sangat Puas \\
\hline Penting & 4 & Puas \\
\hline Cukup Penting & 3 & Cukup Puas \\
\hline Tidak Penting & 2 & Tidak Puas \\
\hline Sangat Tidak Penting & 1 & Sangat Tidak Puas \\
\hline
\end{tabular}

Dari hasil penilaian tingkat kepentingan dan kinerja maka akan dihasilkan perhitungan tingkat kesesuaian dan selanjutnya hasil tersebut dipetakan melalui Diagram Kartesius untuk mengetahui prioritas dari setiap atribut.

4. Analisis penilaian Customer Satisfaction Index (CSI)

Customer Satisfaction Index (CSI) berguna untuk mengetahui tingkat kepuasan konsumen secara menyeluruh dengan melihat tingkat kepentingan dari jenis-jenis pelayanan. Customer Satisfaction Index (CSI) diperlukan karena hasil dari pengukuran CSI ini dapat digunakan sebagai acuan untuk menentukan sasaran-sasaran pengelola terminal di tahuntahun mendatang. Tingkat kepuasan pengguna terminal secara menyeluruh dapat dilihat dengan kriteria pada Tabel 2 berikut: 
Tabel 2. Kriteria Nilai Customer Satisfaction Index (CSI)

\begin{tabular}{|c|l|}
\hline Persentase & \multicolumn{1}{|c|}{ Keterangan } \\
\hline $0 \%-34 \%$ & Sangat Tidak Baik \\
\hline $35 \%-50 \%$ & Kurang Baik \\
\hline $51 \%-65 \%$ & Cukup Baik \\
\hline $66 \%-80 \%$ & Baik \\
\hline $81 \%-100 \%$ & Sangat Baik \\
\hline
\end{tabular}

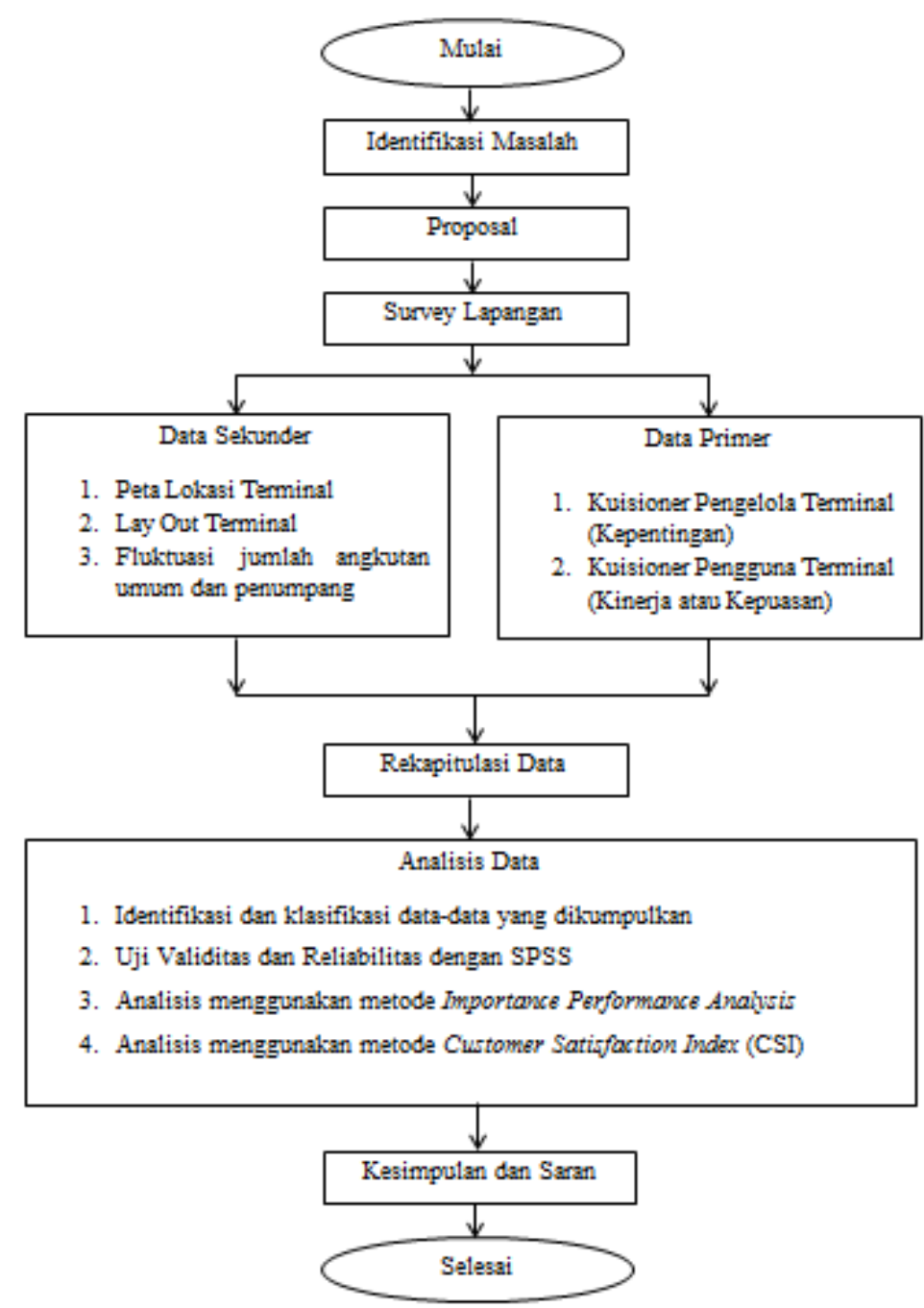

Gambar 1. Diagram Alir Penelitian

\section{HASIL DAN PEMBAHASAN}

\section{Presentasi Data}

Survey dilakukan dengan wawancara dan penyebaran kuisioner kepada para pengelola dan pengguna terminal dengan jumlah masing-masing kuisioner sebanyak 220 responden.

\section{Penentuan Sampel}


Tabel 3. Data rata-rata penumpang (Januari-Juli

\begin{tabular}{|l|c|}
\hline \multicolumn{1}{|c|}{ Bulan } & $\begin{array}{c}\text { Rata-Rata Penumpang } \\
\text { (orang) }\end{array}$ \\
\hline Januari & 296 \\
\hline Februri & 292 \\
\hline Maret & 400 \\
\hline April & 299 \\
\hline Mei & 377 \\
\hline Juni & 1039 \\
\hline Juli & 526 \\
\hline Rata-Rata & 462 \\
\hline
\end{tabular}

Diketahui: $\mathrm{N}=462$ orang

$$
\mathrm{e}=5 \% \text { atau } 0,05
$$

$$
\begin{aligned}
n & =\frac{N}{1+N \times e^{2}} \\
n & =\frac{462}{1+462 \times 0.05^{2}} \\
& =214 \approx 220 \text { sampel }
\end{aligned}
$$

Dari perhitungan slovin di atas, ukuran sampel yang diteliti adalah sebanyak 220 sampel / kuisioner.

\section{Uji Validitas dan Reliabilitas}

\section{Uji Validitas}

Dalam pengujian ini, tiap item akan terbukti valid jika nilai t hitung lebih besar dari $t$ table. Sebaliknya jika nilai t hitung lebih kecil dari $\mathrm{t}$ tabel, maka item angket tersebut tidak valid.

Dalam menentukan persenntase dalam CSI, maka digunakan uji validiitas terlebih dahulu. Untuk mencari jumlah sampel minimal dari pengelola terminal, maka digunakanlah rumus slovin.

Perhitungan slovin:

Dimana: $\mathrm{N}=220$ orang

$$
\begin{aligned}
& n=\frac{N}{1+N \times e^{2}} \\
& n=\frac{220}{1+220 \times 0.05^{2}}=142 \text { sampel }
\end{aligned}
$$

Setelah didapatkan jumlah sampel minimal, dilanjutkan dengan melihat tabel distribusi nilai $r$ tabel signifikansi $5 \%$ dan $1 \%$. Berhubung dalam tabel tersebut tidak ada nilai $\mathrm{N}=142$, maka digunakanlah rumus interpolasi. Perhitungan interpolasi sebagai berikut.

Diketahui: $X_{1}=125$

$$
\begin{aligned}
\mathrm{Y}_{1}=0,176 \\
\mathrm{X}_{2}=150 \\
\mathrm{Y}_{2}=0,159 \\
\mathrm{X}=142 \\
\mathrm{Y}=\mathrm{Y}_{1}+\frac{(X-X 1)}{(X 2-X 1)}\left(\mathrm{Y}_{2}-\mathrm{Y}_{1}\right) \\
=0,176+\frac{(142-125)}{(150-125)}(0,159-0,176) \\
=0,164
\end{aligned}
$$

Dari perhitungan interpolasi, didapatkan nilai $\mathrm{t}$ tabel untuk 142 sampel adalah 0,164.

Dalam pengujian persentase CSI ini, uji validitas dibantu dengan menggunakan software SPSS. Hasil uji validitas dengan menggunakan software SPSS pada persentase CSI dapat dilihat pada tabel 4 .

Dari hasil pengukuran uji validitas pada persentase CSI pada tabel 4 menggunakan software SPSS, maka persentase tersebut berdasarkan data yang valid.

\section{Uji Realibilitas}

Uji reliabilitas berguna untuk mengukur sejauh mana pengukuran dari suatu tes tetap konsisten setelah dilakukan berulang-ulang terhadap subjek dan dalam kondisi yang sama. Hasil uji reliabilitas dapat dilihat pada tabel 5.

Dari hasil pengukuran uji reliabilitas instrumen penelitian persentase CSI pada tabel 5 menggunakan aplikasi SPSS, maka didapatkan bahwa penilaian Persentase CSI merupakan data yang reliabel

\section{Metode Importance Performance Analysis}

Importance Performance Analysis adalah metode analisis dengan tujuan untuk mengetahui kepuasan pengguna terminal terhadap pelayanan yang diberikan padanya. Metode analisis ini dilakukan dengan mengukur jawaban pengguna layanan Terminal Induk PAL 6 Kota Banjarmasin terhadap kuisioner yang dibagikan. Hasil kuisioner dapat dilihat pada tabel 6 
Evaluasi Kinerja Terminal Induk..., Bagus Priambodo Prima ${ }^{(1)}$, Utami Sylvia Lestari ${ }^{(2)}$

Tabel 4. Uji Validiitas Pada Persentase CSI

\begin{tabular}{|l|l|c|c|c|}
\hline Persentase & \multicolumn{1}{|c|}{ Indikator } & Nilai r Hitung & Nilai r Tabel & Keterangan \\
\hline $0 \%-34 \%$ & Sangat Tidak Baik & 0.627 & 0.164 & Valid \\
\hline $35 \%-50 \%$ & Kurang Baik & 0.582 & 0.164 & Valid \\
\hline $51 \%-65 \%$ & Cukup Baik & 0.612 & 0.164 & Valid \\
\hline $66 \%-80 \%$ & Baik & 0.623 & 0.164 & Valid \\
\hline $81 \%-100 \%$ & Sangat Baik & 0.597 & 0.164 & Valid \\
\hline
\end{tabular}

Tabel 5. Hasil Pengukuran Uji Reliabilitas Pada Persentase CSI

\begin{tabular}{|l|l|l|l|l|}
\hline No & Variabel & Nilai r Hitung & Nilai r Tabel & Keterangan \\
\hline 1 & interpretasi non personal & 0.877 & 0.6 & Reliabel \\
\hline
\end{tabular}

Tabel 6. Tingkat Kesesuaian Total

\begin{tabular}{|c|c|c|c|c|c|c|c|c|c|c|c|c|c|c|c|}
\hline \multirow{2}{*}{ No } & \multirow{2}{*}{ Jenis Pelayanan } & \multirow{2}{*}{ Indikator } & \multicolumn{6}{|c|}{ Tingkat Kepentingan } & \multicolumn{6}{|c|}{ Tingkat Kepuasan } & \multirow{2}{*}{$\begin{array}{c}\text { Tingkat } \\
\text { Kesesuaian } \\
\%\end{array}$} \\
\hline & & & 5 & 4 & 3 & 2 & 1 & $\begin{array}{l}\text { Total } \\
\text { Skor }\end{array}$ & 5 & 4 & 3 & 2 & 1 & $\begin{array}{l}\text { Total } \\
\text { Skor }\end{array}$ & \\
\hline $\mathbf{I}$ & \multicolumn{15}{|l|}{ Faktor Internal } \\
\hline \multirow{2}{*}{1} & \multirow{2}{*}{$\begin{array}{l}\text { Informasi yang } \\
\text { jelas dan mudah } \\
\text { dibaca } \\
\text { (Visual/Audio) }\end{array}$} & $\begin{array}{l}\text { a. Letak papan Informasi } \\
\text { sudah stategis }\end{array}$ & 130 & 55 & 35 & 0 & 0 & 975 & 0 & 1 & 119 & 78 & 22 & 539 & 55.28 \\
\hline & & $\begin{array}{l}\text { b. Jumlah papan informasi } \\
\text { sudah mencukupi }\end{array}$ & 130 & 55 & 35 & 0 & 0 & 975 & 0 & 1 & 119 & 79 & 21 & 540 & 55.38 \\
\hline \multirow{2}{*}{2} & \multirow{2}{*}{$\begin{array}{l}\text { Loket agen } \\
\text { perjalanan }\end{array}$} & $\begin{array}{l}\text { a. Memberi jasa pelayanan } \\
\text { yang cukup lama }\end{array}$ & 35 & 73 & 112 & 0 & 0 & 803 & 0 & 36 & 123 & 47 & 14 & 621 & 77.33 \\
\hline & & $\begin{array}{l}\text { b. Jelasnya informasi harga- } \\
\text { harga tiket }\end{array}$ & 35 & 73 & 112 & 0 & 0 & 803 & 0 & 35 & 122 & 49 & 14 & 618 & 76.96 \\
\hline \multirow{2}{*}{3} & \multirow{2}{*}{ Ruang Tunggu } & a. Tempat yang cukup luas & 135 & 57 & 28 & 0 & 0 & 987 & 1 & 45 & 95 & 78 & 1 & 627 & 63.53 \\
\hline & & b. Rapi, bersih \& nyaman & 135 & 57 & 28 & 0 & 0 & 987 & 1 & 44 & 96 & 79 & 0 & 627 & 63.53 \\
\hline \multirow{3}{*}{4} & \multirow{3}{*}{ Tempat ibadah } & $\begin{array}{l}\text { a. Mampu menampung } \\
\text { banyak orang }\end{array}$ & 20 & 78 & 91 & 31 & 0 & 747 & 0 & 47 & 155 & 18 & 0 & 689 & 92.24 \\
\hline & & b. Tempat yang cukup luas & 20 & 78 & 91 & 31 & 0 & 747 & 0 & 46 & 156 & 18 & 0 & 688 & 92.10 \\
\hline & & c. Rapi, bersih \& nyaman & 20 & 78 & 91 & 31 & 0 & 747 & 0 & 54 & 151 & 15 & 0 & 699 & 93.57 \\
\hline \multirow{2}{*}{5} & \multirow{2}{*}{ Toilet } & a. Tersedia banyak toilet & 32 & 83 & 102 & 3 & 0 & 804 & 0 & 19 & 80 & 121 & 0 & 558 & 69.40 \\
\hline & & b. Bersih, wangi \& nyaman & 32 & 83 & 102 & 3 & 0 & 804 & 0 & 19 & 80 & 120 & 1 & 557 & 69.28 \\
\hline \multirow{3}{*}{6} & \multirow{3}{*}{ Tempat parkir } & $\begin{array}{l}\text { a. Menampung banyak } \\
\text { kendaraan }\end{array}$ & 86 & 80 & 51 & 3 & 0 & 909 & 0 & 14 & 129 & 77 & 0 & 597 & 65.68 \\
\hline & & b. Area bersih dari sampah & 86 & 80 & 51 & 3 & 0 & 909 & 0 & 13 & 130 & 77 & 0 & 596 & 65.57 \\
\hline & & c. Parkir tertata rapi & 86 & 80 & 51 & 3 & 0 & 909 & 0 & 12 & 127 & 80 & 1 & 590 & 64.91 \\
\hline \multirow[b]{2}{*}{7} & \multirow[b]{2}{*}{ Ruang terbuka hijau } & a. Areanya luas & 23 & 50 & 105 & 42 & 0 & 714 & 0 & 47 & 113 & 59 & 1 & 646 & 90.48 \\
\hline & & $\begin{array}{l}\text { b. Rindang, rapi, bersih \& } \\
\text { nyaman }\end{array}$ & 23 & 50 & 105 & 42 & 0 & 714 & 0 & 50 & 119 & 50 & 1 & 658 & 92.16 \\
\hline \multirow{2}{*}{8} & \multirow{2}{*}{$\begin{array}{l}\text { Fasilitas istirahat } \\
\text { dan penginapan } \\
\text { bagi penumpang }\end{array}$} & a.Tempat yang cukup luas & 0 & 11 & 46 & 104 & 59 & 449 & 0 & 0 & 30 & 101 & 89 & 381 & 84.86 \\
\hline & & b. Rapi, bersih \& nyaman & 0 & 11 & 46 & 104 & 59 & 449 & 0 & 0 & 29 & 88 & 103 & 366 & 81.51 \\
\hline \multirow{2}{*}{9} & \multirow{2}{*}{$\begin{array}{l}\text { Fasilitas penitipan } \\
\text { barang }\end{array}$} & $\begin{array}{l}\text { a. Mampu menampung } \\
\text { banyak barang }\end{array}$ & 42 & 105 & 62 & 10 & 1 & 837 & 0 & 1 & 65 & 58 & 96 & 411 & 49.10 \\
\hline & & b. Tertara rapi & 42 & 105 & 62 & 10 & 1 & 837 & 0 & 1 & 69 & 56 & 94 & 417 & 49.82 \\
\hline 10 & $\begin{array}{l}\text { Tangga dan } \\
\text { eskalator }\end{array}$ & a. Bersih dan nyaman & 0 & 0 & 105 & 87 & 28 & 517 & 0 & 8 & 92 & 83 & 37 & 511 & 98.84 \\
\hline \multirow{2}{*}{11} & \multirow{2}{*}{$\begin{array}{l}\text { Fasilitas } \\
\text { Telekomunikasi } \\
\text { (internet, telepon } \\
\text { dan TV) }\end{array}$} & $\begin{array}{l}\text { a. Fasilitas telekomunikasi } \\
\text { sudah memadai }\end{array}$ & 46 & 74 & 82 & 18 & 0 & 808 & 0 & 0 & 10 & 124 & 86 & 364 & 45.05 \\
\hline & & b. Fasilitas mudah diakses & 46 & 74 & 82 & 18 & 0 & 808 & 0 & 0 & 10 & 124 & 86 & 364 & 45.05 \\
\hline
\end{tabular}


Evaluasi Kinerja Terminal Induk..., Bagus Priambodo Prima ${ }^{(1)}$, Utami Sylvia Lestari ${ }^{(2)}$

\begin{tabular}{|c|c|c|c|c|c|c|c|c|c|c|c|c|c|c|c|}
\hline \multirow{2}{*}{ No } & \multirow{2}{*}{ Jenis Pelayanan } & \multirow{2}{*}{ Indikator } & \multicolumn{6}{|c|}{ Tingkat Kepentingan } & \multicolumn{6}{|c|}{ Tingkat Kepuasan } & \multirow{2}{*}{$\begin{array}{c}\text { Tingkat } \\
\text { Kesesuaian } \\
\%\end{array}$} \\
\hline & & & 5 & 4 & 3 & 2 & 1 & $\begin{array}{l}\text { Total } \\
\text { Skor }\end{array}$ & 5 & 4 & 3 & 2 & 1 & $\begin{array}{l}\text { Total } \\
\text { Skor }\end{array}$ & \\
\hline 12 & $\begin{array}{l}\text { Fasilitas bagasi } \\
\text { pelayanan barang }\end{array}$ & $\begin{array}{l}\text { a. Mampu menampung } \\
\text { banyak barang }\end{array}$ & 0 & 0 & 23 & 107 & 90 & 373 & 0 & 0 & 23 & 89 & 108 & 355 & 95.17 \\
\hline \multirow{2}{*}{13} & \multirow{2}{*}{$\begin{array}{l}\text { Fasilitas } \\
\text { persampahaan }\end{array}$} & $\begin{array}{l}\text { a. Jumlah tempat sampah } \\
\text { yang mencukupi }\end{array}$ & 86 & 88 & 46 & 0 & 0 & 920 & 0 & 3 & 88 & 129 & 0 & 534 & 58.04 \\
\hline & & $\begin{array}{l}\text { b. Letak tempat sampah yang } \\
\text { strategis }\end{array}$ & 86 & 88 & 46 & 0 & 0 & 920 & 0 & 4 & 87 & 129 & 0 & 535 & 58.15 \\
\hline \multirow{2}{*}{14} & \multirow{2}{*}{ Rumah makan } & $\begin{array}{l}\text { a. Banyak warung yang } \\
\text { tersedia }\end{array}$ & 29 & 79 & 112 & 0 & 0 & 797 & 1 & $\begin{array}{c}11 \\
4\end{array}$ & 102 & 3 & 0 & 773 & 96.99 \\
\hline & & $\begin{array}{l}\text { b. Lokasi tempat makan yang } \\
\text { strategis }\end{array}$ & 29 & 79 & 112 & 0 & 0 & 797 & 1 & $\begin{array}{c}11 \\
4\end{array}$ & 102 & 3 & 0 & 773 & 96.99 \\
\hline 15 & $\begin{array}{l}\text { Fasilitas dan } \\
\text { Petugas kebersihan }\end{array}$ & $\begin{array}{l}\text { a. Petugas dan fasilitas } \\
\text { kebersihan yang } \\
\text { mencukupi }\end{array}$ & 95 & 88 & 37 & 0 & 0 & 938 & 0 & 18 & 101 & 90 & 11 & 566 & 60.34 \\
\hline \multirow{2}{*}{16} & \multirow{2}{*}{$\begin{array}{l}\text { Tempat istirahat } \\
\text { awak kendaraan }\end{array}$} & a.Tempat yang cukup luas & 0 & 68 & 89 & 48 & 15 & 650 & 0 & 2 & 69 & 128 & 21 & 492 & 75.69 \\
\hline & & b. Rapi, bersih \& nyaman & 0 & 68 & 89 & 48 & 15 & 650 & 0 & 0 & 59 & 120 & 41 & 458 & 70.46 \\
\hline \multirow{2}{*}{17} & \multirow{2}{*}{ Area merokok } & $\begin{array}{l}\text { a. Area merokok yang cukup } \\
\text { luas }\end{array}$ & 15 & 98 & 73 & 34 & 0 & 754 & 0 & 0 & 10 & 125 & 85 & 365 & 48.41 \\
\hline & & b. Rapi, bersih \& nyaman & 15 & 98 & 73 & 34 & 0 & 754 & 0 & 0 & 9 & 127 & 84 & 365 & 48.41 \\
\hline 18 & $\begin{array}{l}\text { Lampu penerangan } \\
\text { ruangan }\end{array}$ & $\begin{array}{l}\text { a. Penerangan yang sudah } \\
\text { mencukupi }\end{array}$ & 97 & 58 & 51 & 14 & 0 & 898 & 0 & 25 & 158 & 36 & 1 & 647 & 72.05 \\
\hline \multirow{2}{*}{19} & \multirow{2}{*}{$\begin{array}{l}\text { Fasilitas pengisian } \\
\text { baterai (charging } \\
\text { corner) }\end{array}$} & $\begin{array}{l}\text { a. Banyak tempat charging } \\
\text { corner yang tersedia }\end{array}$ & 71 & 91 & 45 & 13 & 0 & 880 & 0 & 11 & 156 & 50 & 3 & 615 & 69.89 \\
\hline & & $\begin{array}{l}\text { b. Lokasi tempat charging } \\
\text { corner yang strategis }\end{array}$ & 71 & 91 & 45 & 13 & 0 & 880 & 0 & 15 & 151 & 51 & 3 & 618 & 70.23 \\
\hline 20 & Fasilitas keamanan & $\begin{array}{l}\text { a. Jumlah petugas keamanan } \\
\text { yang mencukupi }\end{array}$ & 112 & 82 & 26 & 0 & 0 & 966 & 0 & 90 & 64 & 62 & 4 & 680 & 70.39 \\
\hline \multirow{2}{*}{21} & \multirow{2}{*}{ Ruang anak-anak } & a. Ruang yang cukup luas & 0 & 61 & 92 & 45 & 22 & 632 & 0 & 0 & 59 & 61 & 100 & 399 & 63.13 \\
\hline & & b. Rapi, bersih \& nyaman & 0 & 61 & 92 & 45 & 22 & 632 & 0 & 0 & 59 & 59 & 102 & 397 & 62.82 \\
\hline
\end{tabular}

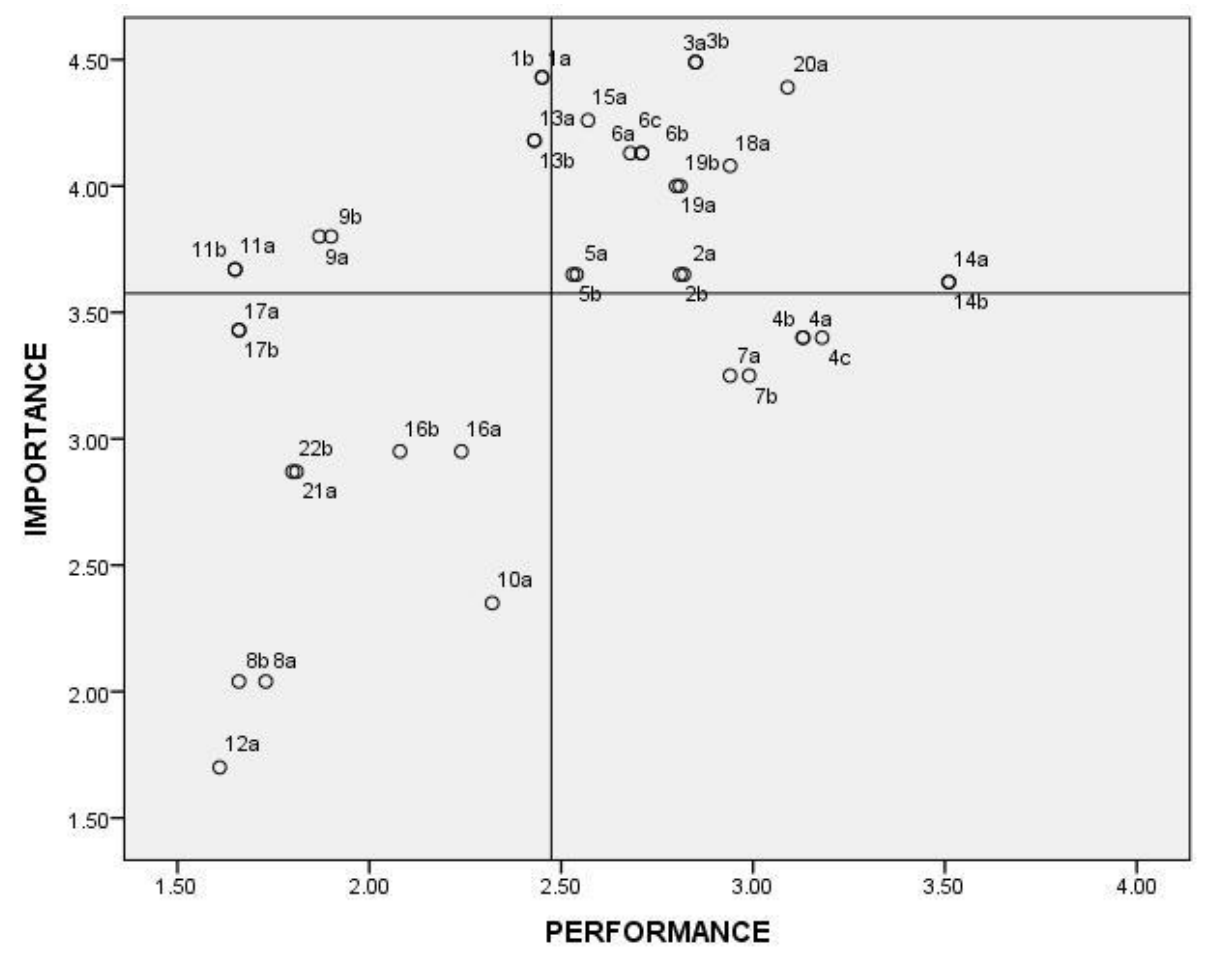

Gambar 2. Diagram Kartesius 
Evaluasi Kinerja Terminal Induk..., Bagus Priambodo Prima ${ }^{(1)}$, Utami Sylvia Lestari ${ }^{(2)}$

Tabel 7. Ringkasan Kuadran Diagram Kartesius

\begin{tabular}{|c|c|c|}
\hline Nomor Kuadran & Jenis Pelayanan & Indikator \\
\hline \multirow{8}{*}{$\begin{array}{c}\text { Kuadran I } \\
\text { (Prioritas Utama) }\end{array}$} & \multirow{2}{*}{$\begin{array}{l}\text { Informasi yang jelas dan mudah } \\
\text { dibaca (Visual/Audio) }\end{array}$} & a. Letak papan Informasi sudah stategis \\
\hline & & b. Jumlah papan informasi sudah mencukupi \\
\hline & \multirow{2}{*}{ Fasilitas penitipan barang } & a. Mampu menampung banyak barang \\
\hline & & b. Tertara rapi \\
\hline & \multirow{2}{*}{$\begin{array}{l}\text { Fasilitas Telekomunikasi (internet, } \\
\text { telepon dan TV) }\end{array}$} & a. Fasilitas telekomunikasi sudah memadai \\
\hline & & b. Fasilitas mudah diakses \\
\hline & \multirow{2}{*}{ Fasilitas persampahaan } & a. Jumlah tempat sampah yang mencukupi \\
\hline & & b. Letak tempat sampah yang strategis \\
\hline \multirow{16}{*}{$\begin{array}{c}\text { Kuadran II } \\
\text { (Pertahankan) }\end{array}$} & \multirow{2}{*}{ Loket agen perjalanan } & a. Memberi jasa pelayanan yang cukup lama \\
\hline & & b. Jelasnya informasi harga-harga tiket \\
\hline & \multirow{2}{*}{ Ruang Tunggu } & a. Tempat yang cukup luas \\
\hline & & b. Rapi, bersih \& nyaman \\
\hline & \multirow{2}{*}{ Toilet } & a. Tersedia banyak toilet \\
\hline & & b. Bersih, wangi \& nyaman \\
\hline & \multirow{3}{*}{ Tempat parkir } & a. Menampung banyak kendaraan \\
\hline & & b. Area bersih dari sampah \\
\hline & & c. Parkir tertata rapi \\
\hline & \multirow{2}{*}{ Rumah makan } & a. Banyak warung yang tersedia \\
\hline & & b. Lokasi tempat makan yang strategis \\
\hline & Fasilitas dan Petugas kebersihan & $\begin{array}{l}\text { a. Petugas dan fasilitas kebersihan yang } \\
\text { mencukupi }\end{array}$ \\
\hline & Lampu penerangan ruangan & a. Penerangan yang sudah mencukupi \\
\hline & \multirow{2}{*}{$\begin{array}{l}\text { Fasilitas pengisian baterai (charging } \\
\text { corner) }\end{array}$} & a. Banyak tempat charging corner yang tersedia \\
\hline & & b. Lokasi tempat charging corner yang strategis \\
\hline & Fasilitas keamanan & a. Jumlah petugas keamanan yang mencukupi \\
\hline \multirow{10}{*}{$\begin{array}{c}\text { Kuadran III } \\
\text { (Prioritas Rendah) }\end{array}$} & \multirow{2}{*}{$\begin{array}{l}\text { Fasilitas istirahat dan penginapan } \\
\text { bagi penumpang }\end{array}$} & a.Tempat yang cukup luas \\
\hline & & b. Rapi, bersih \& nyaman \\
\hline & Tangga dan eskalator & a. Bersih dan nyaman \\
\hline & Fasilitas bagasi pelayanan barang & a. Mampu menampung banyak barang \\
\hline & \multirow{2}{*}{ Tempat istirahat awak kendaraan } & a.Tempat yang cukup luas \\
\hline & & b. Rapi, bersih \& nyaman \\
\hline & \multirow{2}{*}{ Area merokok } & a. Area merokok yang cukup luas \\
\hline & & b. Rapi, bersih \& nyaman \\
\hline & \multirow[t]{2}{*}{ Ruang anak-anak } & a. Ruang yang cukup luas \\
\hline & & b. Rapi, bersih \& nyaman \\
\hline \multirow{5}{*}{$\begin{array}{l}\text { Kuadran IV } \\
\text { (Berlebihan) }\end{array}$} & \multirow{3}{*}{ Tempat ibadah } & a. Mampu menampung banyak orang \\
\hline & & b. Tempat yang cukup luas \\
\hline & & c. Rapi, bersih \& nyaman \\
\hline & \multirow{2}{*}{ Ruang terbuka hijau } & a. Areanya luas \\
\hline & & b. Rindang, rapi, bersih \& nyaman \\
\hline
\end{tabular}


Berdasarkan tabel 6, dapat dilihat bahwa tingkat kesesuaian yang paling rendah adalah Fasilitas Telekomunikasi (internet, telepon dan TV) $(45,05 \%)$. Hal ini menunjukan bahwa para penumpang merasa sangat tidak puas terhadap Fasilitas Telekomunikasi (internet, telepon dan TV) saat ini. Untuk tingkat kesesuaian total ratarata dari pelayanan yang ada diperoleh nilai sebesar $(70,74 \%)$ yang artinya secara keseluruhan kinerja pelayanan Terminal Induk PAL 6 Kota Banjarmasin menurut kriteria nilai Customer Satisfaction Index (CSI) berada pada kategori Baik. Hasil diagram kartesius dapat dilihat pada gambar 2. Penjelasan atribut-atribut pelayanan yang terbagi menjadi empat kuadran dapat dilihat pada tabel 7 .

\section{PENUTUP}

\section{Kesimpulan}

Dari hasil penelitian terhadap Kinerja Terminal Induk PAL 6 Kota Banjarmasin, dapat ditarik beberapa kesimpulan yaitu:

1. Secara keseluruhan Terminal Induk Kota PAL 6 Kota Banjarmasin telah memenuhi standar terminal tipe B dan dari analisis kinerja terminal didapatkan bahwa fasilitas yang diberikan Terminal Induk PAL 6 Kota Banjarmasin kepada pengguna berjalan dengan baik. Namun, untuk kebutuhan parkir di area kedatangan dan keberangkatan bus untuk trayek AKAP masih berada diluar area terminal. Begitu juga untuk penjualan tiket bus AKAP berada di luar area terminal. Area terminal sendiri penuh dengan cold AKDP sehingga tidak ada ruang untuk bertempatnya bus AKAP. Kebersihan area kedatangan dan keberangkatan kurang di jaga kebersihannya, selain dari kesadaran pengguna terminal juga dari pihak terminal menempatkan tong sampah dengan jumlah yang minim. Terminal Induk PAL 6 Kota Banjarmasin baik ditinjau dari aspek tata ruang maupun peraturan penentuan terminal tipe $\mathrm{B}$, secara umum telah memenuhi syarat - syarat yang ditentukan.

2. Dari hasil diagram kartesius, ada beberapa indikator pelayanan masih belum memberikan kinerja yang maksimal. Indicator tersebut diantaranya:

a. Letak papan informasi yang masih belum strategis b. Jumlah papan informasi yang masih belum mencukupi

c. Fasilitas penitipan barang yang belum mampu menaampung banyak barang

d. Fasilitas penitipan barang yang belum tertata rapi

e. Fasilitas telekomunikasi yang belum memadai

f. Fasilitas telekomunikasi yang masih susah diakses

g. Jumlah tempat sampah yang belum mencukupi

h. Letak tempat sampah yang belum strategis Kedelapan indikator peelayanaan ini berada pada Kuadran I yang artinya pelayanan tersebut penting sedangkan kinerja pelayanan pada kenyataannya belum sesuai dari apa yang diharapkan.

3. Dari hasil diagram kartesius, ada beberapa indikator pelayanan masih belum memberikan kinerja yang maksimal tetapi menurut pengelola, pelayanan tersebut dianggap kurang penting. Sehingga dalam usaha peningkatan kinerja ini harus difikirkan penting tidaknya pelayanan tersebut. Indicator tersebut diantaranya:

a. Fasilitas istirahat dan penginapan bagi penumpang yang masih dianggap sempit

b. Keadaan tangga dan escalator yang masih kotor dan kurang nyaman

c. Fasilitas bagasi pelayanan barang belum mampu menampung banyak barang

d. Tempat istirahat awak kendaraan yang masih dianggap sempit

e. Tempat istirahat awak kendaraan yang belum tertata rapi, kotor dan kurang nyaman

f. Area merokok yang belum ada

g. Ruang anak-anak yang belum ada

4. Dari hasil diagram kartesius, ada beberapa indikator pelayanan sudah memberikan kinerja yang cukup memuaskan sehingga indicator pelayanan ini harus dipertahankan. Indicator tersebut diantaranya:

a. Loket agen perjalanan memberikan jasa pelayanan yang cukup lama

b. Jelasnya informasi harga-harga tiket pada loket agen perjalanan

c. Ruang tunggu yang cukup luas

d. Ruang tunggu keadaan rapi, bersih \& nyaman

e. Tersedia banyak toilet

f. Toilet keadaan Bersih, wangi \& nyaman 
g. Tempat parkir mampu menampung banyak kendaraan

h. Area parkir bersih dari sampah

i. Parkir tertata rapi

j. Banyak tempat makan yang tersedia

k. Lokasi tempat makan yang strategis

1. Petugas dan fasilitas kebersihan yang mencukupi

m. Penerangan yang sudah mencukupi

n. Banyak tempat charging corner yang tersedia

o. Lokasi tempat charging corner yang strategis

p. Jumlah petugas keamanan yang mencukupi

q. Musholla mampu menampung banyak orang

r. Musholla yang cukup luas

s. Musholla keadaan rapi, bersih \& nyaman

t. Area ruang terbuka hijau cukup luas

u. Keadaan ruang terbuka hijau yang rindang, rapi, bersih \& nyaman

\section{Saran}

Untuk meningkatkan tingkat pelayanan Terminal Induk PAL 6 Kota Banjarmasin maka ada beberapa hal yang perlu diperhatikan, antara lain:

1. Pelayanan yang sudah berjalan dengan optimal seperti Loket agen perjalanan, Ruang Tunggu, Toilet (jumlah minimal), Rumah makan, Fasilitas dan Petugas kebersihan, Lampu penerangan ruangan, Fasilitas pengisian baterai (charging corner), Fasilitas keamanan, Tempat ibadah, Tempat parkir, dan Ruang terbuka hijau supaya dipertahankan bahkan ditingkatkan lagi kinerja pelayanan tersebut.

2. Untuk peningkatan kinerja pada Luas ruang utk duduk istirahat bagi penumpang, Luas ruang utk tidur penginapan bagi penumpang, Kondisi tangga, Luas bagasi, Luas ruang untuk duduk istirahat awak kendaraan, Luas ruang untuk tidur istirahat awak kendaraan, Luas ruang atau tempat area merokok, Lokasi area merokok, Luas ruang anak-anak, dan Kondisi dan pelayaanan ruangan harus diihat dari seberapa penting pelayanan tersebut.

3. Untuk loket pembelian tiket yang sudah ada di area terminal supaya segera difungsikan.
4. Untuk penelitian lanjutan, dapat diamati kapan saja yang termasuk waktu normal dan waktu terpadat kedatangan penumpang pada berbagai jurusan agar dapat meningkatkan kelancaran operasional terminal.

5. Demi peningkatan fungsi dari Terminal Induk PAL 6 Kota Banjarmasin maka perlu diadakan penelitian lainnya terhadap fasilitasfasilitas lain yang ada.

\section{DAFTAR PUSTAKA}

Arikunto, S. (2013). Prosedur Penelitian: Suatu Pendekatan Praktik. Jakarta: Rineka Cipta.

Azwar, Saifudin. (1986). Validitas dan Reliabilitas. Jakarta: Rineka Cipta

Bahri, Syaiful. (2004). Penilaian Variabel Keputusan Karyawan Menggunakan Metode Analisis Kepentingan dan Analisis Kuadran (Studi Kasus Karyawan PDAM Kota Kandangan). Jurnal Info Teknik Volume 5 No 2, Desember 2004, 89-95

Crompton dan Duray," Importance Performance Analysis",1985.

Direktorat Jenderal Perhubungan Darat, Menuju Lalu Lintas dan Angkutan Jalan Tertib, Direktorat Jenderal Perhubungan Darat, 1995

Ghozali, Imam, (2009). Aplikasi analisis multivariate dengan program spss, Edisi Keempat, Penerbit Universitas Diponegoro.

J. Supranto. (1996). Statistik Teori dan Aplikasi. Jilid I, Edisi Kelima, Jakarta.

Keputusan Menteri Perhubungan No 31 tahun 1995. Terminal Transportasi Jalan

Keputusan Menteri Perhubungan No 74 tahun 2014. Terminal Transportasi Jalan

Latu, T.M. dan Everett, A.M. (2000). Review of Satisfaction Research and Measurement Approaches. New Zealand: Wellington.

Peraturan Menteri Perhubungan Republik Indonesia. (2015). Penyelenggaraan Terminal Penumpang Angkutan Jalan.

Sugiyono. (2008). Metode Penelitian Kuantitatif Kualitatif dan $R \& D$. Bandung: ALFABETA

Supranto, Johannes. (2006). Pengukuran Tingkat Kepuasan Pelanggan Untuk Menaikkan Pangsa Pasar. Jakarta: PT Asdi Mahasatya. Suryabrata, Sumadi. (2004). Metodologi Penelitian. Yogyakarta: Pustaka Pelajar 